\title{
Editorial
}

\section{The Need for Physician Leaders}

Seth W. Wolk, MD, MHSA ${ }^{1,2,3}$

\section{Abstract}

\section{Description}

Almost all care in a healthcare organization flows through their physicians, who are usually viewed as the de facto leaders in almost all clinical settings. Physicians have a disproportionate impact on how care is delivered and also have a disproportionate responsibility to lead change. Effective organizational physician leaders create an environment in which their colleagues are able to successfully exercise their skills and knowledge and are convinced that their efforts contribute to improved patient care.

Author affiliations are listed at the end of this article.

Correspondence to: Seth Wolk, MD, MHSA 2190 East 11th Avenue, \#221 Denver, CO 80206 (swwolk@umich.edu)

\section{Keywords}

physicians; leadership; graduate medical education; internship and residency; health services administration

Why is physician leadership increasingly important? Almost all care in a healthcare organization flows through their fingers either literally or via their keystrokes. They usually are viewed as the de facto leaders in almost all clinical settings. As a group, they are the organization's highest compensated group of employees. It's highly unlikely that any organization can realize its goals if its highest compensated employees' daily activities are not aligned with the organization's goals. For these reasons and others, physicians have a disproportionate impact on how care is delivered and also have a disproportionate responsibility to lead change.

Construction of new facilities, merger and acquisition activity and operational efficiency are critical factors that senior healthcare executives believe determine the trajectory of their organizations. Although these and related factors are no doubt important, I believe that the velocity that healthcare organizations improve both their clinical care and administrative processes are the two dominant determinants of an organization's position in the marketplace 5-10 years in the future. The former, care improvement velocity, is largely dependent upon physicians.

Let's start with a poorly kept secret: Physicians are not humans; however, they are closely related to Homo sapiens. Let's just say they're "humanish." Understanding why physicians are unique actors in the heathcare system and how they got that way is essential in understanding how to effectively lead them.

Physicians are different. They're not born different, but sometime between their early twenties to mid-thirties, they differentiate from others in their age group. This period coincides with medical school and residency training. Although correlation does not equal causation, this 10-15 year period of physical, academic, emotional and social immersion in the medical profession is a likely contributor to their change.

The 4 years of medical school and subsequent residency training are not an efficient experience. The current system was designed to teach students how they as individual, independent actors should care for patients - because at the time when the architecture of medical education was defined a century ago, doctors largely worked independent of each other. Today, doctors work within very complex systems. There are processes through which multiple caregivers interact. These processes are embedded within value networks that define how various actors interact. It varies by hospital, medical school and specialty department. But

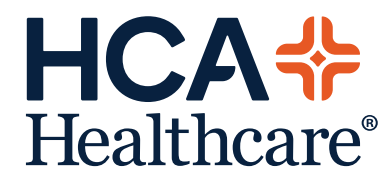
Emerald Medical Education

HCA Healthcare
Journal of Medicine 
in general, there is little in the medical training of physicians that teaches them how to create, administer, lead and improve the way people work together in the healthcare system.

Residencies themselves would be called "cults" by many members of society. These programs share many artifacts of cults including highly specialized skills, a unique language, beliefs and lore and well-defined hierarchy. Unfortunately, residencies also share a distrust of others not in the same specialty. Additionally, national specialty societies tend to reinforce these beliefs long after physicians complete their training. Given these influences, and the evaluation and reward system for individual performance, one shouldn't wonder why most physicians are not better members of a high-powered team upon completion of their training.

Physicians must work effectively in today's complex care delivery environment and need effective physician leaders to pull them past historical boundaries and their generally strong bias for the status quo. Most physicians innately know what great leadership is. They can recall rotations in their training where they were exposed to an outstanding senior resident who inspired the team to accomplish goals far beyond what could individually be achieved. The ensuing esprit de corps made work enjoyable and one looked forward to coming to work. Yet, many forget those lessons as they leave training and embark on full-time clinical roles. Over time, clinicians and executives develop very different skills and mental models of the world. Some examples are listed in Table 1.

Physicians have many attributes needed for great leadership: high intelligence, drive and a desire to serve others. The challenge for physi- cians who aspire to organizational leadership is to continue to "own" what makes them outstanding clinicians while shifting their focus from self to others. They have spent decades to become an "expert". To lead requires a different set of competencies that must be learned and practiced. But most importantly, effective leaders' focus shifts to making others successful and developing the organizational conditions to let others' greatness arise. This shift in focus is usually very, very difficult for those who have been on the expert pathway as long as physicians.

For those physicians whom either desire or are asked to transition to organizational leadership, formal training in the following areas is essential:

- Operational and financial management

- Emotional intelligence

- Data science (The study of the extraction of generalizable knowledge from data.)

- Quality and safety science

- Population management

- Utilization management

- Information technology

- Talent management

Although the path to a senior organizational leadership role is difficult, physicians have a number of attributes that will assist them:

- Are focused on the outcomes and used to taking responsibility for them

- Are highly intelligent and multifaceted

- Possess a passion for solving complex problems

- Are exceptional learners

- Perform well under pressure and have been tested in the past

- Have high expectations of self and others

- Have a strong sense of purpose

Table 1. Differences Between Physicians and Executives ${ }^{1}$

Clinicians

\section{Executives}

$\begin{array}{ll}\text { - } & \text { Doers } \\ \text { - } & 1: 1 \text { interactions } \\ \text { - } & \text { Reactive philosophy } \\ \text { - } & \text { Deciders } \\ \text { - } & \text { Value autonomy } \\ \text { - Independent } \\ \text { - Patient advocate } \\ \text { - Identify with profession/specialty } \\ \text { - Speak the language of Medicine }\end{array}$

- Planners and designers

- 1:n interactions

- Proactive philosophy

- Accept delayed results

- Delegators

- Value collaboration

- Participative

- Organization/population advocate

- Identify with organization

- Speak the language of Finance 
Organizational physician leaders ultimately still need to lead and align both physicians and non-physicians. Below are some lessons in leading physicians that I have painfully learned.

Deeply involve physicians in the design and execution of initiatives. Don't just allow lip service or perfunctory review. Specifically, ask them to design/develop potential solution sets. Most physicians are superb problem solvers. That's what they do on a daily basis. However, clearly define the problem, define the design guardrails and define the financial constraints.

One will need to devote much more time explaining the "why" underlying the initiative (figure 5-10X the time allotted for "normal" humans). Eventually you can get to the "how" and the "when." But remember physicians are trained to be skeptical, it's a foundational component of the differential diagnosis process. They're going to look for reasons why the initiative won't work and will ask many questions. Replies should be honest. Physicians have the most sensitive hogwash meters on earth.

Utilize Max Weber's framework for social action: ${ }^{2}$

1. Appeal to their ethos (shared purpose); remind them why they chose Medicine (relieve suffering and improve the human condition)

2. Appeal to their self-interest; tie their financial incentives to organizational goals

3. Appeal to their traditions; use activities such as dress traditions and communication to signal "this is the way we do things here."

4. Appeal to their competitive nature; most physicians are extraordinarily competitive, receiving a "B" greatly dismays them.

5. Appeal to their need for respect; carefully use data to leverage peer pressure.

Ultimately, effective organizational physician leaders create an environment in which their colleagues are able to successfully exercise their skills and knowledge and are convinced that their efforts contribute to a noble cause. Successful leaders are nearly always genuine and optimistic in their attitudes. All organizational leaders and those they lead need to remember the sacredness of the physician-patient relationship. Shifting economics, advancing technologies and changes in regulation will redefine the role of the physician. But, the purity of that relationship will never change, unless physician leaders allow it to change. ${ }^{3}$

\section{Conflicts of Interest}

The author declares he has no conflicts of interest.

\section{Author Affiliations}

1. Department of Health Management and Policy, University of Michigan, Ann Arbor, MI

2. NuBrick Partners

3. Health Management Academy, Arlington, VA

\section{References}

1. Guthrie MB. Challenges in developing physician leadership and management. Front Health Serv Manage. 1999;15(4):3-26. https://doi. org/10.1097/01974520-199904000-00002

2. Lee TH. An Epidemic of Empathy in Healthcare: How to Deliver Compassionate, Connected Patient Care That Creates a Competitive Advantage. McGraw-Hill Education; 2015:205.

3. Gewertz BL, Logan DC. The Best Medicine: A Physician's Guide to Effective Leadership. New York: Springer; 2014:90. 